\title{
Removal of Organic Impurities from Water Using a Reactor with Photoactive Refill
}

\author{
Joanna Grzechulska-Damszel \\ Institute of Chemical and Environment Engineering, West Pomeranian University of Technology in Szczecin, Pułaskiego 10, \\ 70-322 Szczecin, Poland \\ Correspondence should be addressed to Joanna Grzechulska-Damszel, joanna.grzechulska@zut.edu.pl
}

Received 17 March 2009; Accepted 20 April 2009

Recommended by Mohamed Sabry Abdel-Mottaleb

The aim of the presented work was the removal of phenol from water using a reactor with photoactive refill. Titanium dioxide (Chemical Factory "Police" Poland) was immobilized on the base material as a thin layer from the alcoholic suspension followed by thermal stabilization. The glass fabric was applied as a support for the titania coating. The results of studies revealed that the titania coatings show a high photocatalytic activity toward the phenol decomposition in water. The complete removal of phenol was achieved in the relatively short time of 23 hours. The prepared coatings exhibit high stability in repeated cycles of water treatment. The proposed reactor with photoactive refill solves the problem of necessity of replacement of the reactor or the parts of the reactor when the photocatalysts activity decreases. In the case of activity drop of the photocatalyst, only the photoactive refill can be easily replaced.

Copyright ( 2009 Joanna Grzechulska-Damszel. This is an open access article distributed under the Creative Commons Attribution License, which permits unrestricted use, distribution, and reproduction in any medium, provided the original work is properly cited.

\section{Introduction}

Advance Oxidation Processes (AOPs) have been reported to be useful for photooxidation of organic pollutants in wastewater [1-9]. Among the various Advanced Oxidation Processes employed in water treatment, heterogeneous semiconductor photocatalysis shows great importance due to its ability to destroy a wide range of organic pollutants at ambient temperature and pressure, without generation of harmful byproducts [10-24]. The most commonly used photocatalyst is $\mathrm{TiO}_{2}$. Titanium dioxide has essentially proved itself to be the best material for environmental purification because of its many desirable properties. $\mathrm{TiO}_{2}$ is a cheap, readily available material capable of oxidation of a wide range of organic pollutants into harmless compounds, often leading to complete mineralization of organics.

The use of photocatalysis has been proved to be a good choice to achieve an effective elimination of phenolic compounds from waters [25-42]. Also, phenol is usually taken as a model compound for advanced wastewater treatment studies [43-45].
The photocatalytic processes can operate using catalyst suspended in the solution or immobilized on various supports. Photocatalytic reactors with suspended catalyst give much better contact between the photocatalyst and dissolved impurities comparing to reactors with immobilized catalyst. However, in this case the step of separation of the catalyst is necessary, which increases the overall costs of the process. Different researchers have tried to minimize these problems by immobilizing $\mathrm{TiO}_{2}$ on various solid supports or on the reactor walls, which eliminates arduous step of separation [46-56]. Titanium dioxide was immobilized on various supports and using various methods. Immobilization of the photocatalyst on the reactor walls or other parts of the reactor shows disadvantages when the activity of the catalyst decreases, and it has to be replaced. Thus, the better solution is to immobilize the photocatalyst on the replaceable elements that can be easily removed and placed again in the reactor. The other advantage of such supports is to provide a good contact of the treated medium with the photocatalyst surface and also a good penetration of light in the reactor. A flexible textiles seemed to be adequate support for the photoactive titania coatings. However, textiles are an 
organic materials and can itself undergo the photocatalytic degradation.

The aim of the presented work was the removal of organic impurities from water using a reactor with photoactive refill. Titanium dioxide (Chemical Factory "Police" Poland) was immobilized on the base material as a thin layer from the alcoholic suspension followed by thermal stabilization. In case of activity drop of the photocatalyst, only the photoactive refill can be easily replaced.

\section{Experimental}

The commercial anatase form of titanium dioxide produced by Chemical Factory "Police" (Poland) was used as a photocatalyst. Phenol (POCh S.A., Poland) was used as a model organic compound. Titanium dioxide was immobilized on the base material from the alcoholic solution followed by thermal stabilization. The support for titania photoactive coating was a glass fabric produced by "Pabiantex" factory (Poland). The glass fabric with titania coating was a replaceable photoactive refill placed in the reactor where the process of water purification was conducted.

The process of photocatalytic oxidation of phenol was conducted using a laboratory installation (Figure 1) where the main component of the system was the flow reactor (Trojan Technologies, Canada). This is a cylindrical reactor with length of approximately $29.5 \mathrm{~cm}$ and the diameter of $6.8 \mathrm{~cm}$. The mercury lamp emitting UV radiation in the range of $250-800 \mathrm{~nm}$, with high maximum at 254,436 , and $546 \mathrm{~nm}$, was placed inside the reactor, in the center. The photoactive refill was also placed inside the reactor in a way to stick the inner walls of the reactor.

The photocatalyst was fixed to the glass fabric according to the following procedure. The suspension of $\mathrm{TiO}_{2}$ in ethanol was sonicated for 1 hour with a frequency of $40 \mathrm{kHz}$. The glass fabric ( prepared suspension and then dried for at $105^{\circ} \mathrm{C}$. The procedure was repeated twice. After that the coating was stabilized by thermal treatment at the temperature of $150^{\circ} \mathrm{C}$ overnight. The excess of the immobilized photocatalyst was rinsed by flowing water through the reactor before the photocatalytic process.

The solution of phenol, with the initial concentration of $20 \mathrm{mg} / \mathrm{dm}^{3}$, was pumped to the reactor by peristaltic pump from the container and was circulated through the reactor with the flow rate of $36 \mathrm{dm}^{3} / \mathrm{h}$. The volume of the reaction solution was $2.5 \mathrm{dm}^{3}$. The amount of the solution inside the reactor was approximately $1 \mathrm{dm}^{3}$. The changes of phenol concentration in the solution were determined by absorbance measurement at maximal absorption wavelength $270 \mathrm{~nm}$ (Jasco V-530 spectrometer, Japan). Total organic carbon (TOC) concentration was measured by "multi N/C 2000" analyzer (Analytik Jena, Germany). Total dissolved solids (TDS) content, conductivity, and $\mathrm{pH}$ of the solution (Ultrameter 6P, Myron L Company, USA) were also monitored during the process. The reaction solution circulated in the reactor for 15 minutes without illumination to obtain the adsorption equilibrium. The adsorption of phenol onto photocatalyst surface was low, only about $1 \%$ (by weight).

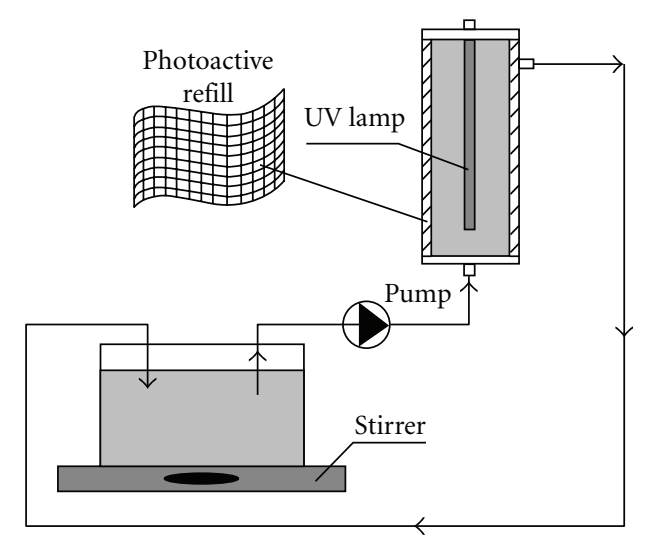

Figure 1: The scheme of installation for the process of photocatalytic oxidation of phenol.

\section{Results and Discussion}

The experiments of the photocatalytic degradation of phenol were conducted for the initial concentration of $20 \mathrm{mg} / \mathrm{dm}^{3}$. The volume of the treated solution was $2.5 \mathrm{dm}^{3}$. The first test reaction of photocatalytic decomposition of phenol was conducted until the complete decay of phenol in the reaction solution (phenol presence was not detected by UV/Vis analysis). The next tests were conducted for 10 hours.

At the beginning of studies blank experiments were performed. No decomposition occurred when an aqueous solution of phenol flowed through the reactor in the dark, and the direct photolysis was also negligible. Decomposition of phenol in the solution could only be observed with the simultaneous presence of $\mathrm{TiO}_{2}$ and of UV light. Therefore, it can be stated that in the presence of $\mathrm{TiO}_{2}$ a true heterogeneous catalytic regime takes place.

Figure 2 presents the changes in phenol concentration during the photocatalytic process for four tests preformed with the same photoactive refill. The concentration of phenol decreases with the time of the process. As can be seen from Figure 2, the decrease in phenol concentration is the highest during the first hours of the process. After that, the rate of decrease of concentration of phenol decelerates; however, the complete removal of phenol from the treated solution was obtained. During the first test the complete removal of phenol was observed after 23 hours of the process. In the second tests, the concentration of phenol in the solution after 10 hours of illumination was a little higher comparing to the first one; however, the third and the fourth tests showed comparable time of decomposition as the second one.

The reaction of photocatalytic phenol decomposition followed the first-order reaction kinetics concerning to phenol concentration. A plot of $\ln \left(C_{0} / C\right)$ versus time represents a straight line (Figure 2), the slope of which upon the linear regression equals the apparent first-order rate constant $k^{\prime}$ according to the equation of the Langmuir-Hinshelwood model:

$$
r=-\frac{d C}{d t}=\frac{k_{r} k_{a} C}{1+k_{a} C}
$$




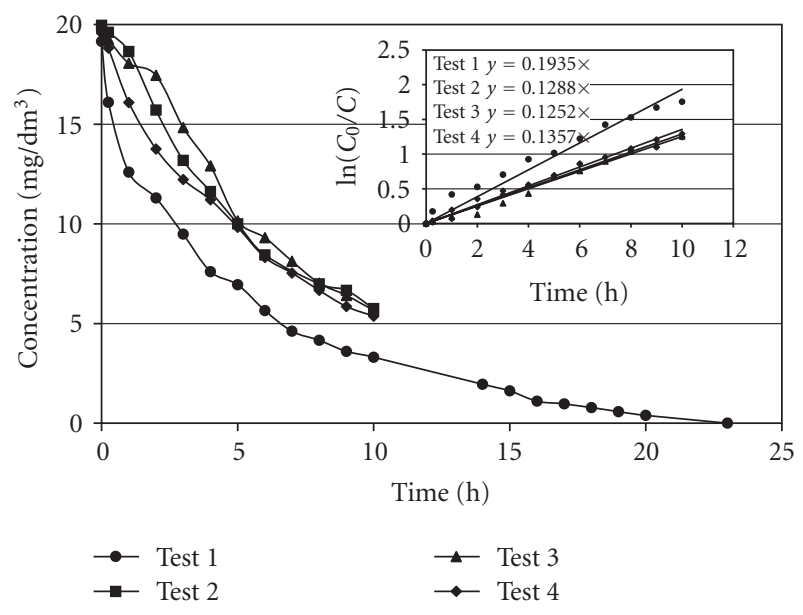

Figure 2: The changes in phenol concentration during the photocatalytic process.

TABLE 1: Apparent first-order rate constants $\left(k^{\prime}\right)$ and linear regression coefficients $\left(R^{2}\right)$ of phenol photodecomposition reactions.

\begin{tabular}{lcc}
\hline Test no. & $k^{\prime}$ & $R^{2}$ \\
\hline 1 & 0.1935 & 0.9821 \\
2 & 0.1288 & 0.9896 \\
3 & 0.1252 & 0.9864 \\
4 & 0.1357 & 0.9905 \\
\hline
\end{tabular}

which can be simplified to a apparent first-order equation:

$$
\ln \left(\frac{C_{0}}{C}\right)=k_{r} k_{a} t=k^{\prime} t
$$

Table 1 lists the values of $k^{\prime}$ and the linear regression coefficients of photodegradation of phenol for each test performed. According to the values in the table, the appropriate linear relationship appears well.

The changes in phenol concentration were monitored by $\mathrm{UV} / \mathrm{Vis}$ spectroscopy. Figure 3 presents an example UV/Vis spectra recorded during the photocatalytic process of phenol decomposition. The progressive fading of the absorption peak at the wavelength of $270 \mathrm{~nm}$ is observed indicating the decrease of phenol concentration in the consecutive samples taken for the analysis during the process.

Together with the decrease of the concentration of phenol in the reaction solution with the time of the process, the decrease of TOC concentration was observed (Figure 4). Total disappearance of the reactant was obtained after 23 hours of the process while the organic carbon was still present in the solution after this time of the photocatalytic process. TOC concentration in the starting solution was equal to $14.4 \mathrm{mg} / \mathrm{dm}^{3}$ for the first test. After the photocatalytic process was completed, the TOC concentration decreased to $6.56 \mathrm{mg} / \mathrm{dm}^{3}$, which gives over $54 \%$ of removal of organic carbon from the solution. The decrease of TOC concentration was the result of the aromatic ring opening and subsequent decomposition of intermediate products formed; however, the complete mineralization of phenol was not achieved. The time of photocatalytic process should be

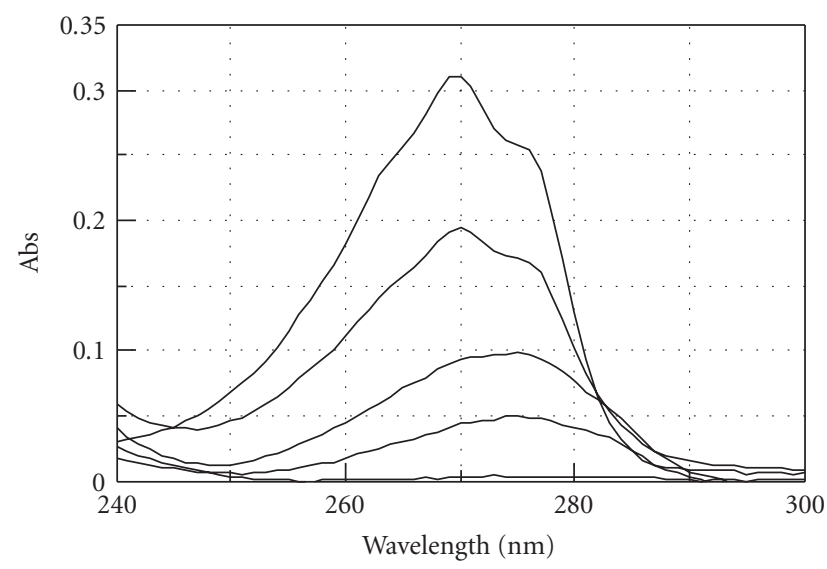

FIGURE 3: The example spectra of the reaction solution recorded during the photocatalytic process. From top: starting solution, after 1 hour of the process, after 5 hours of the process, after 10 hours of the process, and after 23 hours of the process.

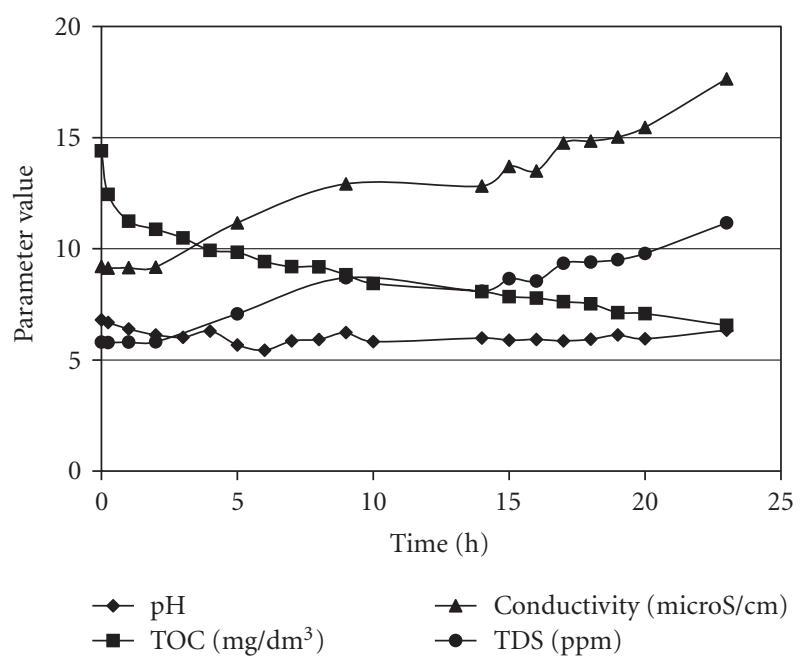

FIgURE 4: The changes of parameters monitored during the photocatalytic process.

elongated to obtain the oxidation of phenol to the final products: $\mathrm{CO}_{2}$ and $\mathrm{H}_{2} \mathrm{O}$.

The values of TDS, conductivity, and $\mathrm{pH}$ measured during the process give a better view to the degradation reaction. The changes of these parameters are presented in Figure 4. The data presented on Figure 4 refer to the first test of decomposition of phenol. For the other three tests the tendency of changes was similar. The conductivity and TDS values tend to increase with the time of the process. This indicates the mineralization of organic molecules and increase of dissolved species present in the solution. However, this also indicates that the decomposition process was not complete; this is to say it did not lead to full mineralization of the reactant, since in such a case the values of TDS and conductivity would settle at the some value and remained constant. The analysis of organic carbon in the reaction solution confirms the above statement. 


\section{Conclusions}

Conclusions are listed as follows.

(i) The process of the photocatalytic removal of phenol can be successfully conducted in the reactor with photoactive refill presented in these studies.

(ii) The photoactive refill applied in the studies is prepared using a very simple method and in the case of decrease of photoactivity can be easily replaced.

(iii) The titania coating shows a high photocatalytic activity toward the model organic compound (phenol) decomposition in water.

(iv) The prepared coating exhibits high stability in repeated cycles of water treatment.

(v) The proposed reactor with photoactive refill solves the problem of necessity of replacement of the reactor or the parts of the reactor when the photocatalyst activity decreases.

(vi) Application of glass fabric is advantageous since it is resistant to UV light and does not undergo the photocatalytic decomposition on the contrary to the natural fabrics.

\section{Acknowledgment}

This work was financed by the Polish Government in the framework of a Grant (2006-2009).

\section{References}

[1] Handbook, "Advanced photochemical oxidation processes," Tech. Rep. EPAl6251R-981004, United States Environmental Protection Agency, Washington, DC, USA, 1998.

[2] R. Munter, "Advanced oxidation processes—current status and prospects," Proceedings of the Estonian Academy of Sciences. Chemistry, vol. 50, no. 2, pp. 59-80, 2001.

[3] R. Munter, S. Preis, J. Kallas, M. Trapido, and Y. Veressinina, "Advanced oxidation processes (AOPs): water treatment technology for the twenty-first century," Finnish Chemical Journal, vol. 28, no. 5, pp. 354-362, 2001.

[4] A. Mills and S.-K. Lee, "A web-based overview of semiconductor photochemistry-based current commercial applications," Journal of Photochemistry and Photobiology A, vol. 152, no. 13, pp. 233-247, 2002.

[5] S. Esplugas, J. Giménez, S. Contreras, E. Pascual, and M. Rodríguez, "Comparison of different advanced oxidation processes for phenol degradation," Water Research, vol. 36, no. 4, pp. 1034-1042, 2002.

[6] M. Rodríguez, "Fenton and UV-vis based advanced oxidation processes in wastewater treatment: degradation, mineralization and biodegradability enhancement," Universitat de Barcelona, Facultat de Química, Departament d'Enginyeria Química i Metallúrgia, Programa de Doctorado de Ingeniería Química Ambiental, Biennio 1998-2000, Barcelona, Spain 2003.

[7] P. R. Gogate and A. B. Pandit, "A review of imperative technologies for wastewater treatment-I: oxidation technologies at ambient conditions," Advances in Environmental Research, vol. 8, no. 3-4, pp. 501-551, 2004.
[8] P. R. Gogate and A. B. Pandit, "A review of imperative technologies for wastewater treatment-II: hybrid methods," Advances in Environmental Research, vol. 8, no. 3-4, pp. 553597, 2004.

[9] M. I. Maldonado, P. C. Passarinho, I. Oller, et al., "Photocatalytic degradation of EU priority substances: a comparison between $\mathrm{TiO}_{2}$ and fenton plus photo-fenton in a solar pilot plant," Journal of Photochemistry and Photobiology A, vol. 185, no. 2-3, pp. 354-363, 2007.

[10] M. R. Hoffmann, S. T. Martin, W. Choi, and D. W. Bahnemann, "Environmental applications of semiconductor photocatalysis," Chemical Reviews, vol. 95, no. 1, pp. 69-96, 1995.

[11] A. L. Linsebigler, G. Lu, and J. T. Yates Jr., "Photocatalysis on $\mathrm{TiO}_{2}$ surfaces: principles, mechanisms, and selected results," Chemical Reviews, vol. 95, no. 3, pp. 735-758, 1995.

[12] M. Schiavello, Heterogeneous Photocatalysis, John Willey \& Sons, New York, NY, USA, 1997.

[13] A. Mills and S. LeHunte, "An overview of semiconductor photocatalysis," Journal of Photochemistry and Photobiology A, vol. 108, no. 1, pp. 1-35, 1997.

[14] J.-M. Herrmann, "Heterogeneous photocatalysis: fundamentals and applications to the removal of various types of aqueous pollutants," Catalysis Today, vol. 53, no. 1, pp. 115$129,1999$.

[15] A. Fujishima, T. N. Rao, and D. A. Tryk, "Titanium dioxide photocatalysis," Journal of Photochemistry and Photobiology C, vol. 1, no. 1, pp. 1-21, 2000.

[16] D. S. Bhatkhande, V. G. Pangarkar, and A. A. C. M. Beenackers, "Photocatalytic degradation for environmental applicationsa review," Journal of Chemical Technology and Biotechnology, vol. 77, no. 1, pp. 102-116, 2002.

[17] M. Kaneko and I. Okura, Photocatalysis. Science and Technology, Kodansha, Tokyo, Japan; Springer, Berlin, Germany, 2002.

[18] D. Bahnemann, "Photocatalytic water treatment: solar energy applications," Solar Energy, vol. 77, no. 5, pp. 445-459, 2004.

[19] K. Hashimoto, H. Irie, and A. Fujishima, " $\mathrm{TiO}_{2}$ photocatalysis: a historical overview and future prospects," Japanese Journal of Applied Physics, vol. 44, no. 12, pp. 8269-8285, 2005.

[20] A. Mills and M. McFarlane, "Current and possible future methods of assessing the activities of photocatalyst films," Catalysis Today, vol. 129, no. 1-2, pp. 22-28, 2007.

[21] J.-M. Herrmann, C. Duchamp, M. Karkmaz, et al., "Environmental green chemistry as defined by photocatalysis," Journal of Hazardous Materials, vol. 146, no. 3, pp. 624-629, 2007.

[22] A. Fujishima, X. Zhang, and D. A. Tryk, "Heterogeneous photocatalysis: from water photolysis to applications in environmental cleanup," International Journal of Hydrogen Energy, vol. 32, no. 14, pp. 2664-2672, 2007.

[23] U. I. Gaya and A. H. Abdullah, "Heterogeneous photocatalytic degradation of organic contaminants over titanium dioxide: a review of fundamentals, progress and problems," Journal of Photochemistry and Photobiology C, vol. 9, no. 1, pp. 1-12, 2008.

[24] N. S. Allen, M. Edge, J. Verran, J. Stratton, J. Maltby, and C. Bygott, "Photocatalytic titania based surfaces: environmental benefits," Polymer Degradation and Stability, vol. 93, no. 9, pp. 1632-1646, 2008.

[25] K. Okamoto, Y. Yamamoto, H. Tanaka, M. Tanaka, and A. Itaya, "Heterogeneous photocatalytic decomposition of phenol over $\mathrm{TiO}_{2}$ powder," Bulletin of the Chemical Society of Japan, vol. 58, pp. 2015-2022, 1985. 
[26] K. Okamoto, Y. Yamamoto, H. Tanaka, and A. Itaya, "Kinetics of heterogeneous photocatalytic decomposition of phenol over anatase $\mathrm{TiO}_{2}$ powder," Bulletin of the Chemical Society of Japan, vol. 58, pp. 2023-2027, 1985.

[27] S. Cheng, S.-J. Tsai, and Y.-F. Lee, "Photocatalytic decomposition of phenol over titanium oxide of various structures," Catalysis Today, vol. 26, no. 1, pp. 87-96, 1995.

[28] A. W. Morawski, J. Grzechulska, and K. Kałucki, "A new method for preparation of potassium-pillared layered titanate applied in photocatalysis," Journal of Physics and Chemistry of Solids, vol. 57, no. 6-8, pp. 1011-1017, 1996.

[29] Z. Ding, G. Q. Lu, and P. F. Greenfield, "Role of the crystallite phase of $\mathrm{TiO}_{2}$ in heterogeneous photocatalysis for phenol oxidation in water," The Journal of Physical Chemistry B, vol. 104, no. 19, pp. 4815-4820, 2000.

[30] A. M. Peiró, J. A. Ayllón, J. Peral, and X. Doménech, " $\mathrm{TiO}_{2}-$ photocatalyzed degradation of phenol and ortho-substituted phenolic compounds," Applied Catalysis B, vol. 30, no. 3-4, pp. 359-373, 2001.

[31] B. Tryba, A. W. Morawski, and M. Inagaki, "Application of $\mathrm{TiO}_{2}$-mounted activated carbon to the removal of phenol from water," Applied Catalysis B, vol. 41, no. 4, pp. 427-433, 2003.

[32] J. Grzechulska and A. W. Morawski, "Photocatalytic labyrinth flow reactor with immobilized $\mathrm{P} 25 \mathrm{TiO}_{2}$ bed for removal of phenol from water," Applied Catalysis B, vol. 46, no. 2, pp. 415419, 2003.

[33] A. Sobczyński, L. Duczmal, and W. Żmudziński, "Phenol destruction by photocatalysis on $\mathrm{TiO}_{2}$ : an attempt to solve the reaction mechanism," Journal of Molecular Catalysis A, vol. 213, no. 2, pp. 225-230, 2004.

[34] S. Lathasree, A. N. Rao, B. SivaSankar, V. Sadasivam, and K. Rengaraj, "Heterogeneous photocatalytic mineralisation of phenols in aqueous solutions," Journal of Molecular Catalysis A, vol. 223, pp. 101-105, 2004.

[35] D. Vione, C. Minero, V. Maurino, M. E. Carlotti, T. Picatonotto, and E. Pelizzetti, "Degradation of phenol and benzoic acid in the presence of a $\mathrm{TiO}_{2}$-based heterogeneous photocatalyst," Applied Catalysis B, vol. 58, no. 1-2, pp. 79-88, 2005.

[36] Z. Guo, R. Ma, and G. Li, "Degradation of phenol by nanomaterial $\mathrm{TiO}_{2}$ in wastewater," Chemical Engineering Journal, vol. 119, no. 1, pp. 55-59, 2006.

[37] M. H. Priya and G. Madras, "Kinetics of photocatalytic degradation of phenols with multiple substituent groups," Journal of Photochemistry and Photobiology A, vol. 179, no. 3, pp. 256-262, 2006.

[38] C. Karunakaran and R. Dhanalakshmi, "Semiconductorcatalyzed degradation of phenols with sunlight," Solar Energy Materials \& Solar Cells, vol. 92, no. 11, pp. 1315-1321, 2008.

[39] S. Liu, N. Jaffrezic, and C. Guillard, "Size effects in liquidphase photo-oxidation of phenol using nanometer-sized $\mathrm{TiO}_{2}$ catalysts," Applied Surface Science, vol. 255, no. 5, part 2, pp. 2704-2709, 2008.

[40] G. Busca, S. Berardinelli, C. Resini, and L. Arrighi, "Technologies for the removal of phenol from fluid streams: a short review of recent developments," Journal of Hazardous Materials, vol. 160, no. 2-3, pp. 265-288, 2008.

[41] B. Tryba, "Immobilization of $\mathrm{TiO}_{2}$ and $\mathrm{Fe}-\mathrm{C}-\mathrm{TiO}_{2}$ photocatalysts on the cotton material for application in a flow photocatalytic reactor for decomposition of phenol in water,"
Journal of Hazardous Materials, vol. 151, no. 2-3, pp. 623-627, 2008.

[42] C.-H. Chiou, C.-Y. Wu, and R.-S. Juang, "Influence of operating parameters on photocatalytic degradation of phenol in UV/TiO2 process," Chemical Engineering Journal, vol. 139, no. 2, pp. 322-329, 2008.

[43] N. Serpone, G. Sauve, R. Koch, et al., "Standardization protocol of process efficiencies and activation parameters in heterogeneous photocatalysis: relative photonic efficiencies," Journal of Photochemistry and Photobiology A, vol. 94, no. 23, pp. 191-203, 1996.

[44] N. Serpone, "Relative photonic efficiencies and quantum yields in heterogeneous photocatalysis," Journal of Photochemistry and Photobiology A, vol. 104, no. 1-3, pp. 1-12, 1997.

[45] N. Serpone and A. Salinaro, "Terminology, relative photonic efficiencies and quantum yields in heterogeneous photocatalysis - part I: suggested protocol," Pure and Applied Chemistry, vol. 71, no. 2, pp. 303-320, 1999.

[46] A. Fernández, G. Lassaletta, V. M. Jiménez, A. Justo, A. R. González-Elipe, and J.-M. Herrmann, "Preparation and characterization of $\mathrm{TiO}_{2}$ photocatalysts supported on various rigid supports (glass, quartz and stainless steel). Comparative studies of photocatalytic activity in water purification," Applied Catalysis B, vol. 7, no. 1-2, pp. 49-63, 1995.

[47] M. F. J. Dijkstra, A. Michorius, H. Buwalda, H. J. Panneman, J. G. M. Winkelman, and A. A. C. M. Beenackers, "Comparison of the efficiency of immobilized and suspended systems in photocatalytic degradation," Catalysis Today, vol. 66, no. 2-4, pp. 487-494, 2001.

[48] S. Gelover, P. Mondragón, and A. Jiménez, "Titanium dioxide sol-gel deposited over glass and its application as a photocatalyst for water decontamination," Journal of Photochemistry and Photobiology A, vol. 165, no. 1-3, pp. 241-246, 2004.

[49] S. Parra, S. E. Stanca, I. Guasaquillo, and K. R. Thampi, "Photocatalytic degradation of atrazine using suspended and supported $\mathrm{TiO}_{2}$," Applied Catalysis B, vol. 51, no. 2, pp. 107116, 2004.

[50] G. Balasubramanian, D. D. Dionysiou, M. T. Suidan, I. Baudin, and J.-M. Laîné, "Evaluating the activities of immobilized $\mathrm{TiO}_{2}$ powder films for the photocatalytic degradation of organic contaminants in water," Applied Catalysis B, vol. 47, no. 2, pp. 73-84, 2004.

[51] S. Mozia, M. Tomaszewska, and A. W. Morawski, "Decomposition of nonionic surfactant in a labyrinth flow photoreactor with immobilized $\mathrm{TiO}_{2}$ bed," Applied Catalysis B, vol. 59, no. 3-4, pp. 155-160, 2005.

[52] J. Gunlazuardi and W. A. Lindu, "Photocatalytic degradation of pentachlorophenol in aqueous solution employing immobilized $\mathrm{TiO}_{2}$ supported on titanium metal," Journal of Photochemistry and Photobiology A, vol. 173, no. 1, pp. 51-55, 2005.

[53] M. F. J. Dijkstra, A. Michorius, H. Buwalda, H. J. Panneman, J. G. M. Winkelman, and A. A. C. M. Beenackers, "Comparison of the efficiency of immobilized and suspended systems in photocatalytic degradation," Catalysis Today, vol. 66, no. 2-4, pp. 487-494, 2001.

[54] H. D. Mansilla, C. Bravo, R. Ferreyra, et al., "Photocatalytic EDTA degradation on suspended and immobilized $\mathrm{TiO}_{2}$," Journal of Photochemistry and Photobiology A, vol. 181, no. 2-3, pp. 188-194, 2006. 
[55] J. Krýsa, G. Waldner, H. Měšt'ánková, J. Jirkovský, and G. Grabner, "Photocatalytic degradation of model organic pollutants on an immobilized particulate $\mathrm{TiO}_{2}$ layer. Roles of adsorption processes and mechanistic complexity," Applied Catalysis B, vol. 64, no. 3-4, pp. 290-301, 2006.

[56] V. Goetz, J. P. Cambon, D. Sacco, and G. Plantard, "Modeling aqueous heterogeneous photocatalytic degradation of organic pollutants with immobilized $\mathrm{TiO}_{2}$," Chemical Engineering and Processing, vol. 48, no. 1, pp. 532-537, 2008. 


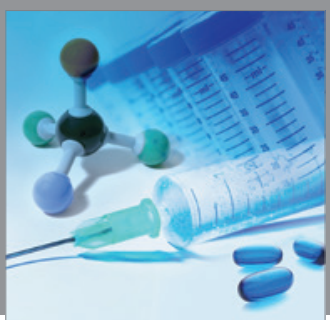

International Journal of

Medicinal Chemistry

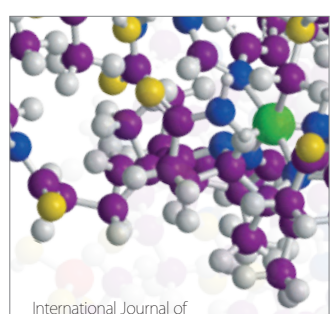

Carbohydrate Chemistry

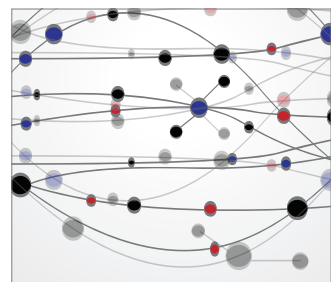

The Scientific World Journal
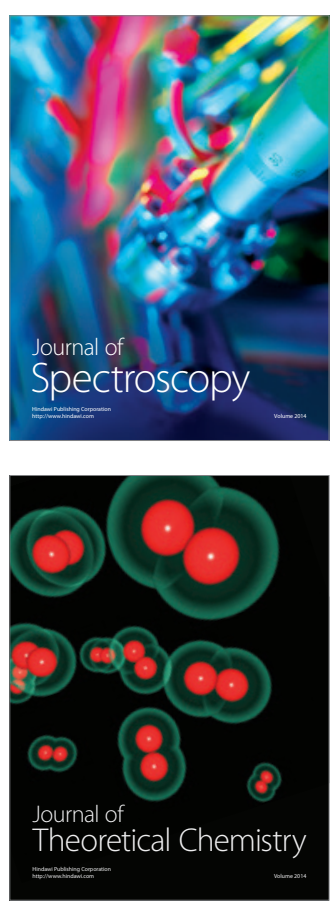
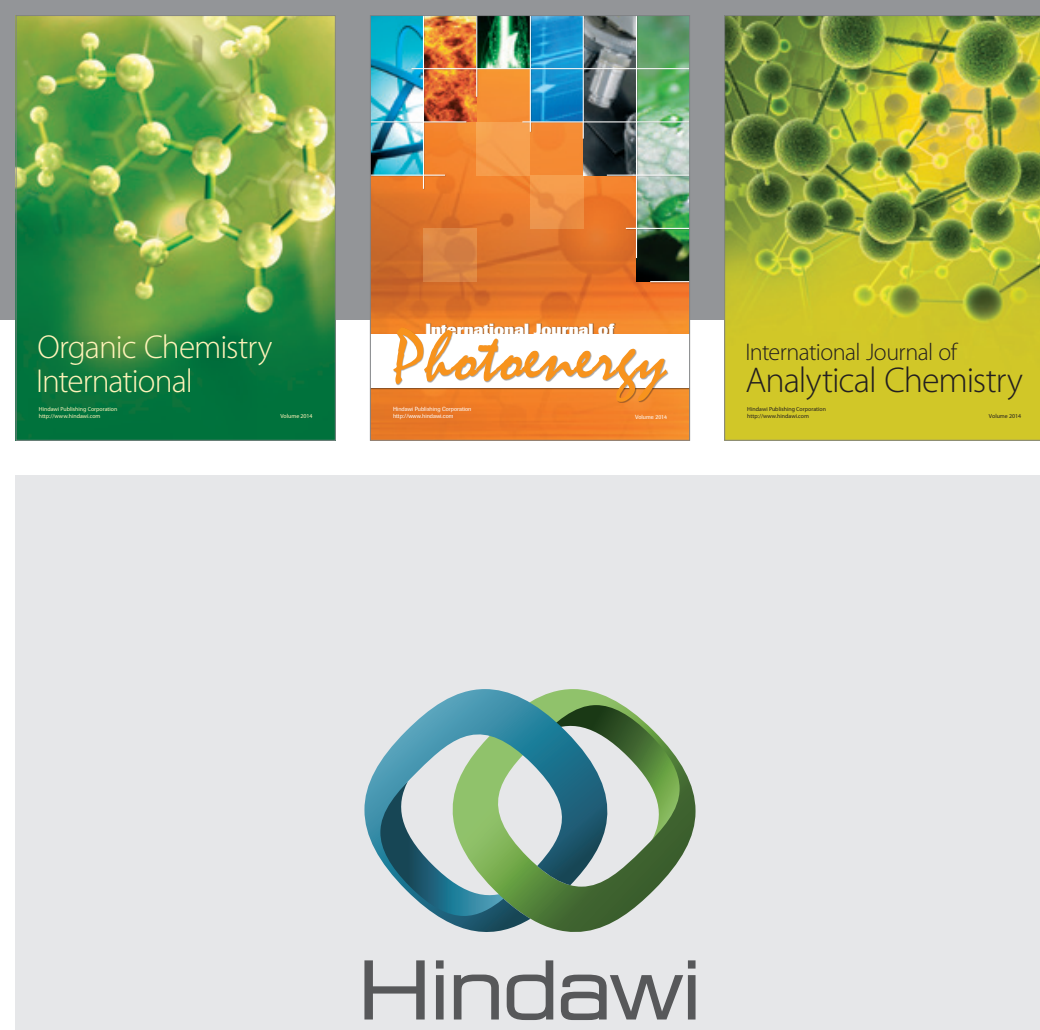

Submit your manuscripts at

http://www.hindawi.com
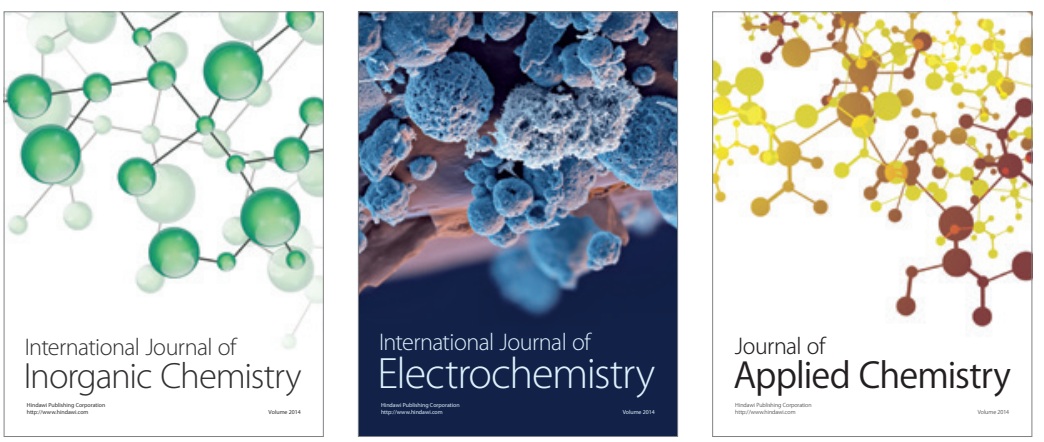

Journal of

Applied Chemistry
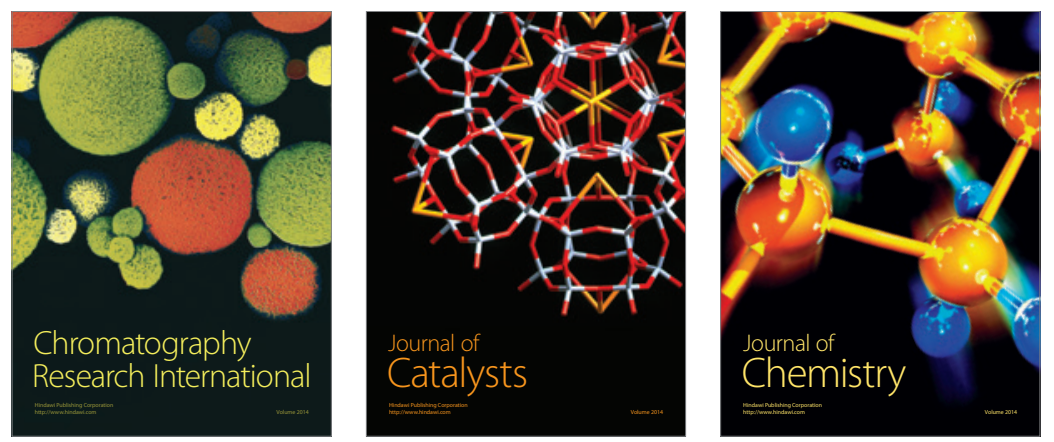
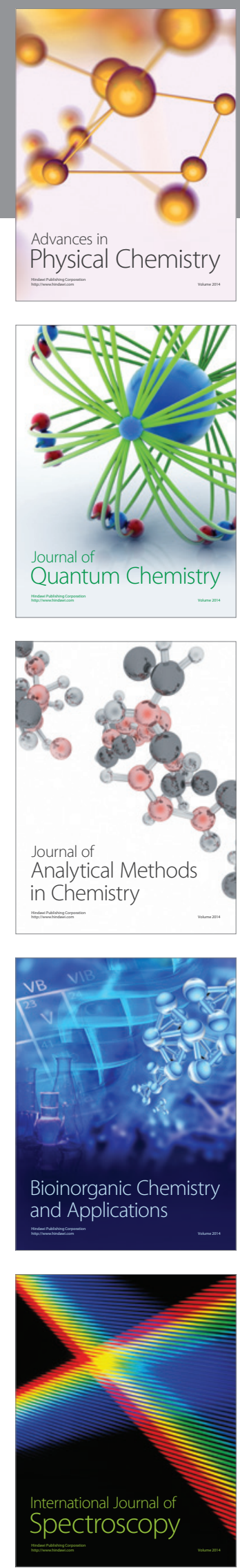